\title{
Genome-wide analysis of the ATP-binding cassette $(A B C)$ transporter gene family in sea lamprey and Japanese lamprey
}

\author{
Jianfeng Ren ${ }^{1}$, Yu-Wen Chung-Davidson ${ }^{2}$, Chu-Yin Yeh², Camille Scott ${ }^{3}$, Titus Brown ${ }^{3,4}$ and Weiming Li $i^{1,2^{*}}$
}

\begin{abstract}
Background: Lampreys are extant representatives of the jawless vertebrate lineage that diverged from jawed vertebrates around 500 million years ago. Lamprey genomes contain information crucial for understanding the evolution of gene families in vertebrates. The ATP-binding cassette (ABC) gene family is found from prokaryotes to eukaryotes. The recent availability of two lamprey draft genomes from sea lamprey Petromyzon marinus and Japanese lamprey Lethenteron japonicum presents an opportunity to infer early evolutionary events of ABC genes in vertebrates.
\end{abstract}

Results: We conducted a genome-wide survey of the $A B C$ gene family in two lamprey draft genomes. A total of 37 $A B C$ transporters were identified and classified into seven subfamilies; namely seven $A B C A$ genes, $10 A B C B$ genes, 10 ABCC genes, three $A B C D$ genes, one $A B C E$ gene, three $A B C F$ genes, and three $A B C G$ genes. The $A B C A$ subfamily has expanded from three genes in sea squirts, seven and nine in lampreys and zebrafish, to 13 and 16 in human and mouse. Conversely, the multiple copies of $A B C B 1-, A B C G 1$-, and $A B C G 2$-like genes found in sea squirts have contracted in the other species examined. $A B C B 2$ and $A B C B 3$ seem to be new additions in gnathostomes (not in sea squirts or lampreys), which coincides with the emergence of the gnathostome-specific adaptive immune system. All the genes in the $A B C D, A B C E$ and $A B C F$ subfamilies were conserved and had undergone limited duplication and loss events. In the sea lamprey transcriptomes, the ABCE and ABCF gene subfamilies were ubiquitously and highly expressed in all tissues while the members in other gene subfamilies were differentially expressed.

Conclusions: Thirteen more lamprey ABC transporter genes were identified in this study compared with a previous study. By concatenating the same gene sequences from the two lampreys, more full length sequences were obtained, which significantly improved both the assignment of gene names and the phylogenetic trees compared with a previous analysis using partial sequences. The ABC gene subfamilies in chordates have undergone obvious expansion or contraction. The ABCA subfamily showed the highest gene expansion rate during chordate evolution. The evolution of $A B C$ transporters in lampreys requires further evaluation because the present results are based on a draft genome.

Keywords: ABC transporter, Evolution, Chordates, Lampreys, RNA-Seq, Gene expression

\footnotetext{
* Correspondence: liweim@msu.edu

'Key Laboratory of Exploration and Utilization of Aquatic Genetic Resources, College of Fisheries and Life Sciences, Shanghai Ocean University, Shanghai 201306, China

${ }^{2}$ Department of Fisheries and Wildlife, Michigan State University, East Lansing, MI 48824, USA

Full list of author information is available at the end of the article
} 


\section{Background}

The ATP-binding cassette $(\mathrm{ABC})$ gene family encodes membrane-spanning proteins that transport a wide variety of substrates (e.g., ions, sugars, amino acids, lipids, lipopolysaccharides, peptides, metals, toxic metabolites, and xenobiotics) across cell membranes. ABC transporters are ubiquitous in all organisms from prokaryotes to eukaryotes [1-4]. Most $\mathrm{ABC}$ proteins contain an ATP-binding domain (also known as the nucleotidebinding domain, NBD) and a transmembrane domain (TMD). The highly conserved NBD contains Walker A, Walker $\mathrm{B}$, and $\mathrm{ABC}$ signature motifs. The NBD binds and hydrolyses ATP, providing energy for substrate transport. The TMD consists of five to six membrane spanning helices that determine substrate specificity [5]. Eukaryotic $\mathrm{ABC}$ transporters are either full transporters with all the required domains in one polypeptide chain (i.e., two NBDs and two TMDs), or half transporters (one NBD and one TMD) that form homo- or heterodimers as the functional units [1-4].

$A B C$ proteins have been divided into eight distinct subfamilies $(\mathrm{A}-\mathrm{H})$ based on the features of their NBDs. Subfamily H, which is closely related to subfamily G, was first identified in fruit fly (Drosophila melanogaster) and later found in insects and zebrafish (Danio rerio), but is absent from plant, worm, yeast, and mammalian genomes $[6,7]$. The remaining seven subfamilies (A-G) have been named ABC1, MDR/TAP, CFTR/MRP, ALD, OABP, GCN20, and White, respectively $[1,8]$. ABC transporters can also be classified functionally as exporters, importers, and non-transport proteins. The exporters and importers are essential for transporting diverse biological substances, whereas the non-transport proteins (subfamilies $\mathrm{E}$ and F) are involved mainly in ribosome biogenesis and translation regulation [9-11].

Many $\mathrm{ABC}$ transporters associated with disease processes have been studied extensively in animal models. $A B C B 1$ (P-glycoprotein) was the first eukaryotic $A B C$ transporter to be identified on the surface of cancer cells [12] where it acts as a multidrug resistance (MDR) efflux transporter that prevents the accumulation of chemotherapeutic drugs inside cancer cells. Some ABC genes have been associated with hereditary diseases such as cystic fibrosis caused by mutations in ABCC7/CFTR (cystic fibrosis transmembrane conductance regulator), adrenoleukodystrophy (ALD) caused by mutations in ABCD1, and cholesterol metabolism disorders caused by mutations in $\mathrm{ABCB} 4, \mathrm{ABCB} 11$, and $\mathrm{ABCC} 2$ [13].

The $A B C$ transporter family with a total of 48 members was first systematically characterized in human (Homo sapiens) [1]. The $\mathrm{ABC}$ transporter genes in mouse (Mus musculus) and fruit fly genomes have been analyzed jointly with their counterparts in the human genome $[1,14]$. Subsequently, genome-wide analyses of $\mathrm{ABC}$ genes have been performed in the nematode Caenorhabditis elegans [15], several arthropod species including mosquito (Anopheles gambiae) [16], silkworm (Bombyx mori), the beetle Tribolium castaneum, honeybee (Apis mellifera) [17-19], water flea (Daphnia pulex) [20], spider mite (Tetranychus urticae) [21], and several fish species including the channel catfish Ictalurus punctatus [22].

The evolution of the $\mathrm{ABC}$ transporter genes has been investigated within the jawed vertebrate lineage (gnathostome) $[7,13,23]$, but not in the jawless vertebrate lineage (lampreys and hagfishes; agnatha). Jawless vertebrates diverge from the jawed vertebrates near 500 million years ago [24], and differ from gnathostomes by a single medially-located nostril and a notochord that persists in adults. Jawless vertebrates also lack hinged jaws, a mineralized skeleton, paired appendages, a pancreas, and spleen [25].

The draft genomes of two lamprey species, the sea lamprey Petromyzon marinus and Japanese lamprey Lethenteron japonicum, have been released recently [24, 26]. These genome data provide resources for investigating $A B C$ gene evolution in early vertebrates. In this study, we conducted a genome-wide survey of the $\mathrm{ABC}$ gene family in sea lamprey and Japanese lamprey, and identified 37 ABC transporters. Phylogenetic analyses divided these $A B C$ genes into seven subfamilies. We also obtained the $\mathrm{ABC}$ gene expression levels in various tissues across different developmental stages in sea lamprey by highthroughput RNA sequencing (RNA-Seq). The patterns of $A B C$ gene expansion or contraction were discussed in the context of chordate evolution.

\section{Results and discussion}

Identification, characterization, and phylogenetic analysis of $A B C$ transporters

The sea lamprey genome is characterized by having many chromosomes ( $\mathrm{n}$ is about 99 ), and is highly repetitive, heterozygous, and GC-rich [27]. The genome was found to undergo programmed genome rearrangements during early embryogenesis, resulting in the deletion of about $20 \%$ of the germline DNA from somatic tissues [28]. Thus, the sea lamprey genome sequences that have been published are more fragmented and cover fewer genes than the genome encodes. Therefore, we assembled a sea lamprey transcriptome from 89 RNA-Seq samples of various tissues across different developmental stages (Additional file 1: Figure S1) that greatly improved the percentage of genes covered. In addition, a draft genome assembly of the Japanese lamprey has been generated recently with DNA from the testis [26], thereby avoiding the DNA deletion that takes place in somatic tissues.

The $A B C$ genes were identified independently in the sea lamprey and Japanese lamprey genomes. These sea lamprey and Japanese lamprey $\mathrm{ABC}$ gene sequences have 
been deposited in GenBank and are presented in the Additional file 2, respectively. A total of $37 \mathrm{ABC}$ transporter genes were identified in the lampreys and 13 more $A B C$ transporter genes were identified in this study compared with the previous analysis in Liu et al [22] (Additional file 3: Table S1). The lengths of mRNA and protein sequences, CDS status, domain structure, and GenBank accession numbers are summarized in Table 1. The phylogenetic analyses grouped the 37 transporter genes into seven subfamilies (Additional file 4: Figure S2): namely, seven $\mathrm{ABCAs}, 10 \mathrm{ABCBs}, 10 \mathrm{ABCCs}$, three $\mathrm{ABCDs}$, one $\mathrm{ABCE}$, three $\mathrm{ABCF}$, and three ABCGs (Table1). The $\mathrm{ABCH}$ subfamily member that was present in zebrafish was not found in the lamprey genomes. In the phylogenetic analyses, the sea squirts Ciona intestinalis and C. savignyi that represent a non-vertebrate chordate lineage were chosen as the outgroups. Detailed evolutionary and phylogenetic analyses of the $\mathrm{ABC}$ genes in lampreys were conducted for each subfamily as described below.

\section{ABCA subfamily}

Seven $A B C A$ genes were identified in the sea lamprey and Japanese lamprey including $A B C A 1 a, A B C A 1 b$, $A B C A 2-A B C A 5$, and $A B C A 12$. These genes all encode full transporter proteins, except $\mathrm{ABCA1b}$, which lacks a NBD because of incomplete sequence (Table 1, Additional file 5: Figure S3). $A B C A 1 b$ and $A B C A 4$ were not found in the previous study by Liu et al [22] and most of the identified $\mathrm{ABCA}$ genes were short fragments and less than half their full length (Additional file 3: Table S1). The phylogenetic analysis supported the member assignment for the lamprey $A B C A$ subfamily and the seven $A B C A$ proteins clustered with their counterparts from other species (Fig. 1).

The lamprey $A B C A 1 \mathrm{a}$ and $\mathrm{ABCA} 1 \mathrm{~b}$ proteins clustered with members of the ABCA1 and ABCA7 from human, mouse and zebrafish. This large clade then clustered with the $A B C A 4$ group with sea squirt $A B C A 1$ members at the base of the whole clade (Fig. 1). The ABCA7 and ABCA1 members from gnathostomes appear as paralogs derived from $A B C A 1$ duplication because two ABCA1 members from the lampreys were at the base of the clade. Two copies of both ABCA1 and ABCA4 encoded in zebrafish may be derived from fish-specific genome duplication because they are also present in most teleost fish [22]. ABCA2 appears before the speciation of lampreys and is generally conserved in vertebrates, but has not been found in some teleost fish examined [22].

Sea squirt ABCA3 proteins were placed at the basal position of the clade including the vertebrate $\mathrm{ABCA} 3$ group, and the mouse $\mathrm{ABCA} 14-\mathrm{ABCA} 16$ group, and $\mathrm{ABCA} 17$ (Fig. 1). This finding implies that mouse $A B C A 14-$ $A B C A 17$ may be derived from the duplication of $A B C A 3$.
The gene arrangement analysis also suggested that they evolved by gene duplication. In the mouse genome, the first exons of $A B C A 17$ and $A B C A 3$ overlap and are transcribed from opposite strands [29]. $A B C A 14-A B C A 16$ are arranged in a tandem head-to-tail cluster on a mouse chromosome and this arrangement is also present in the rat and $\operatorname{dog}$ genomes but only the gene fragments of $A B C A 14-A B C A 16$ remain in human genome [7, 30]. $A B C A 12$ is present in the genomes of all four vertebrates examined (human, mouse, zebrafishand lamprey) while $A B C A 13$ is present only in the human and mouse genomes (Fig. 1).

$A B C A 5$ is conserved throughout all chordates, as indicated by the phylogenetic analysis. In a large clade, the ABCA5 proteins of sea squirts and lamprey were placed at the base whereas the ABCA5s of human, mouse, and zebrafish clustered together in a subclade that included $\mathrm{ABCA6}, \mathrm{ABCA8}$, and $\mathrm{ABCA} 9$ proteins from both mouse and human, as well as a ABCA10 from human (Fig. 1). No counterparts for the ABCA5related genes ( $A B C A 6$ and $A B C A 8-A B C A 10$ ) were identified in lamprey, zebrafish, or other teleost fish [22]. These ABCA5-related genes in the human, dog ( $A B C A 10$ is a pseudogene), and mouse ( $A B C A 8$ is duplicated and $A B C A 10$ is absent) were arranged in a cluster with $A B C A 5$ on the same chromosomes [7, 31]. Other ABCA5-related genes that clustered with $A B C A 5$ have also been found on chicken and Xenopus chromosomes [23, 31]. The phylogenetic and syntenic analyses imply that $A B C A 5$ is evolutionarily conserved and the additions of $A B C A 5$-related genes occurred and expanded through gene duplication after the teleost split with the other vertebrates [32].

In summary, most of the ABCA genes identified in this study were full length after concatenation of the two lamprey sequences and two more ABCA genes were identified than Liu et al [22]. Sea squirts have three members in the ABCA subfamily whereas lamprey and zebrafish have seven and nine, respectively. However, mouse and human possess up to 16 and 13 members, respectively. This finding clearly implies that the ABCA subfamily has undergone expansion through high-frequency gene duplication during chordate evolution.

\section{$A B C B$ subfamily}

A total of $10 \mathrm{ABCB}$ genes were identified in lampreys including $A B C B 1, A B C B 5-A B C B 11, A B C B 1$-like, and $A B C B 10$-like. Four of these genes, $A B C B 5, A B C B 7$, $A B C B 1$-like, and $A B C B 10$-like were not found by Liu et al [22] and most of the gene sequences were shorter than the full length gene sequences identified in the present study. Furthermore, in the previous study $A B C B 1$ was fragmented into two segments that were annotated mistakenly as " $A B C B 4$ " and " $A B C B 5$ " (Additional file 3: 
Table 1 Details of 37 ABC transporter genes and the translated proteins identified in lampreys

\begin{tabular}{|c|c|c|c|c|c|c|c|c|c|c|c|c|}
\hline \multirow[t]{2}{*}{ Gene name } & \multicolumn{4}{|c|}{ Sea lamprey (SL) } & \multicolumn{3}{|c|}{ Japanese lamprey (JL) } & \multicolumn{4}{|c|}{ Concatenation of SL and JL } & \multirow{2}{*}{$\begin{array}{l}\text { Reference } \\
\text { (aa) }\end{array}$} \\
\hline & Acc. No. & $\begin{array}{l}\text { mRNA } \\
(\mathrm{bp})\end{array}$ & $\begin{array}{l}\text { Protein } \\
\text { (aa) }\end{array}$ & $\begin{array}{l}\text { CDS } \\
\text { status }^{\text {a }} \\
\end{array}$ & $\begin{array}{l}\text { mRNA } \\
\text { (bp) }\end{array}$ & $\begin{array}{l}\text { Protein } \\
\text { (aa) }\end{array}$ & $\begin{array}{l}\text { CDS } \\
\text { status }\end{array}$ & $\begin{array}{l}\text { mRNA } \\
\text { (bp) }\end{array}$ & $\begin{array}{l}\text { Protein } \\
\text { (aa) }\end{array}$ & $\begin{array}{l}\text { Domain } \\
\text { structure }\end{array}$ & $\begin{array}{l}\text { CDS } \\
\text { status } \\
\end{array}$ & \\
\hline ABCA1a & KM232912 & 4371 & 1457 & $P$ & 6588 & 2195 & C & 6786 & 2276 & (TMD-NBD)2 & C & 2261 \\
\hline$A B C A 1 b$ & KM232913 & 609 & 203 & $P$ & 4416 & 1471 & $P$ & 4416 & 1471 & TMD-NBD-TMD & P & 2261 \\
\hline$A B C A 2$ & KM232914 & 4614 & 1537 & $P$ & 7053 & 2350 & C & 7521 & 2457 & (TMD-NBD)2 & C & 2433 \\
\hline $\mathrm{ABCA3}$ & KM232915 & 7248 & 1725 & C & 4455 & 1484 & C & 7248 & 1725 & (TMD-NBD)2 & C & 1704 \\
\hline ABCA4 & KM232916 & 3180 & 1059 & $P$ & 6348 & 2116 & C & 6348 & 2116 & (TMD-NBD)2 & C & 2310 \\
\hline ABCA5 & KM232917 & 5366 & 1679 & C & 3762 & 1253 & $P$ & 5366 & 1679 & (TMD-NBD)2 & C & 1642 \\
\hline ABCA12 & KM232918 & 6737 & 1832 & $P$ & 5492 & 1829 & $P$ & 6737 & 1832 & (TMD-NBD)2 & P & 2595 \\
\hline $\mathrm{ABCB} 1$ & KM232919 & 4585 & 1288 & C & 3750 & 1249 & C & 4585 & 1288 & (TMD-NBD)2 & C & 1276 \\
\hline ABCB1-like & KM232920 & 2256 & 751 & $P$ & 3018 & 1005 & $P$ & 3132 & 1043 & TMD-?-TMD-NBD & P & 1276 \\
\hline ABCB5 & - & - & - & - & 3570 & 1189 & C & 3570 & 1336 & (TMD-NBD)2 & C & 1255 \\
\hline ABCB6 & KM232921 & 4180 & 857 & C & 2382 & 793 & C & 4180 & 857 & TMD-NBD & C & 842 \\
\hline ABCB7 & KM232922 & 2241 & 729 & C & - & - & - & 2242 & 729 & TMD-NBD & C & 752 \\
\hline ABCB8 & KM232923 & 2371 & 709 & C & 2118 & 705 & C & 2371 & 709 & TMD-NBD & C & 717 \\
\hline ABCB9 & KM232924 & 3063 & 807 & C & 2385 & 795 & C & 3063 & 807 & TMD-NBD & C & 762 \\
\hline ABCB10 & KM232925 & 3635 & 754 & C & 2265 & 754 & C & 3635 & 754 & TMD-NBD & C & 715 \\
\hline ABCB10-like & KM232926 & 2370 & 790 & C & 2259 & 752 & C & 2370 & 790 & TMD-NBD & C & 715 \\
\hline ABCB11 & KM232927 & 5241 & 1320 & C & 2853 & 950 & $P$ & 5241 & 1320 & (TMD-NBD)2 & C & 1321 \\
\hline $\mathrm{ABCC} 1$ & KM232928 & 1484 & 444 & $P$ & 4044 & 1347 & $P$ & 4658 & 1501 & (TMD-NBD)2 & C & 1528 \\
\hline$A B C C 2$ & KM232929 & 7002 & 1558 & C & 4034 & 1344 & $P$ & 7002 & 1558 & (TMD-NBD)2 & C & 1543 \\
\hline ABCC3a & KM232930 & 5876 & 1556 & C & 4260 & 1419 & $P$ & 5876 & 1556 & (TMD-NBD)2 & C & 1522 \\
\hline$A B C C 3 b$ & KM232931 & 3500 & 1166 & $P$ & 2859 & 952 & $P$ & 3502 & 1166 & (TMD-NBD)2 & P & 1522 \\
\hline $\mathrm{ABCC} 4$ & KM232932 & 4176 & 1303 & C & 2070 & 689 & $P$ & 4176 & 1303 & (TMD-NBD)2 & C & 1325 \\
\hline$A B C C 5$ & KM232933 & 3093 & 1009 & $P$ & 4236 & 1411 & C & 4383 & 1439 & (TMD-NBD)2 & C & 1436 \\
\hline $\mathrm{ABCC7}$ & KM232934 & 4606 & 1466 & C & 3180 & 1059 & $P$ & 4606 & 1466 & (TMD-NBD)2 & C & 1476 \\
\hline $\mathrm{ABCC} 8$ & KM232935 & 4737 & 1578 & C & 4311 & 1436 & $P$ & 4737 & 1578 & (TMD-NBD)2 & C & 1588 \\
\hline ABCC9 & KM232936 & 4850 & 1596 & C & 4383 & 1460 & $P$ & 4850 & 1596 & (TMD-NBD)2 & C & 1588 \\
\hline$A B C C 10$ & KM232937 & 5922 & 1584 & C & 4710 & 1569 & C & 5922 & 1584 & (TMD-NBD)2 & C & 1460 \\
\hline$A B C D 2$ & KM232938 & 2954 & 791 & C & 2379 & 792 & C & 2954 & 791 & TMD-NBD & C & 741 \\
\hline ABCD3 & KM232939 & 1990 & 659 & C & 1980 & 659 & C & 1990 & 659 & TMD-NBD & C & 659 \\
\hline $\mathrm{ABCD} 4$ & KM232940 & 2033 & 633 & C & 1902 & 633 & C & 2033 & 633 & TMD-NBD & C & 606 \\
\hline ABCE1 & KM232941 & 2386 & 599 & C & 1800 & 599 & C & 2386 & 599 & NBD-NBD & C & 599 \\
\hline ABCF1 & KM232942 & 2773 & 740 & C & 2508 & 835 & C & 3037 & 828 & NBD-NBD & C & 837 \\
\hline ABCF2 & KM232943 & 5349 & 614 & C & 1845 & 614 & C & 5349 & 614 & NBD-NBD & C & 628 \\
\hline ABCF3 & KM232944 & 3774 & 712 & C & 2022 & 673 & C & 3774 & 712 & NBD-NBD & C & 709 \\
\hline ABCG2a & KM232945 & 2790 & 703 & C & 2100 & 699 & C & 2790 & 703 & NBD-TMD & C & 657 \\
\hline $\mathrm{ABCG} 2 \mathrm{~b}$ & KM232946 & 2521 & 666 & C & 1737 & 578 & C & 2521 & 666 & NBD-TMD & C & 657 \\
\hline ABCG4 & KM232947 & 1977 & 658 & C & 1959 & 652 & C & 1977 & 658 & NBD-TMD & C & 646 \\
\hline
\end{tabular}

${ }^{\mathrm{a}} \mathrm{P}$ indicates partial sequence, $\mathrm{C}$ indicates complete sequence. ${ }^{\mathrm{b}}$ Reference indicates the length of the protein in mouse

Table S1). The ABCB subfamily includes both full and half transporters. The ABCB1, $\mathrm{ABCB} 5$, and $\mathrm{ABCB} 11$ proteins are full transporters while $\mathrm{ABCB} 1$-like is an incomplete sequence that lacks a NBD. The remaining proteins, $\mathrm{ABCB} 6-\mathrm{ABCB} 10$ and $\mathrm{ABCB} 10-$ like are half transporters
(Table 1, Additional file 5: Figure S3). Compared with the human genome with $11 \mathrm{ABCB}$ transporter genes, lampreys lacked $\mathrm{ABCB} 2-\mathrm{ABCB} 4$. However, two additional genes, $A B C B 1$-like and $A B C B 10$-like were identified in lampreys (Fig. 2). 

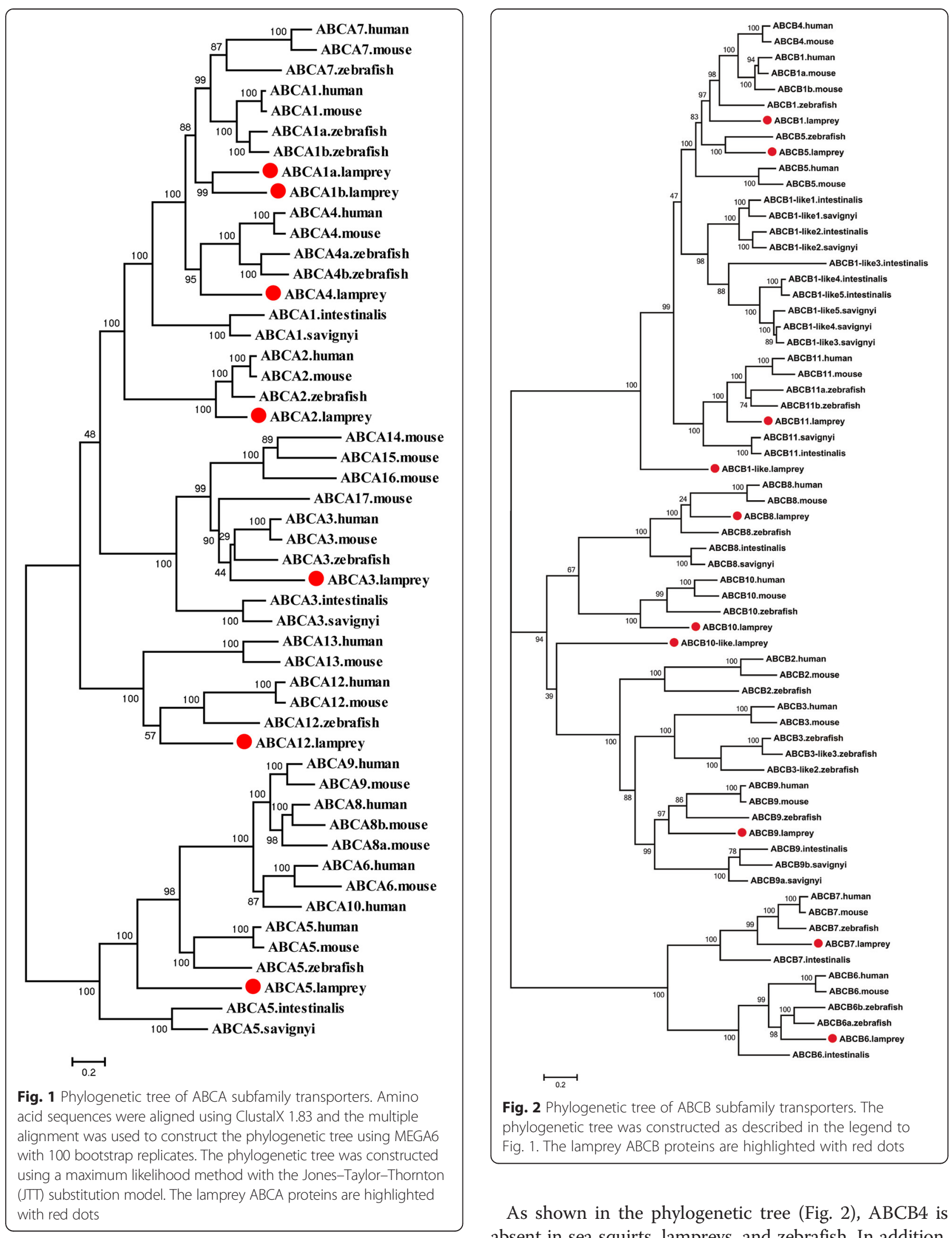

As shown in the phylogenetic tree (Fig. 2), ABCB4 is absent in sea squirts, lampreys, and zebrafish. In addition, the lamprey $\mathrm{ABCB} 1$ and $\mathrm{ABCB} 5$ proteins fell into a large 
subclade that included the ABCB1, ABCB4, and ABCB5 proteins from human, mouse, and zebrafish. This large subclade then grouped with the subclade of five predicted $A B C B 1-l i k e$ proteins from sea squirts. This finding implies that the $A B C B 1$-like genes in sea squirts underwent significant gene loss such that one member remained after the divergence of lampreys with sea squirts or that $A B C B 1$-like underwent Ciona-specific duplications. Gene duplications also occurred and gave rise to new $A B C B$ members such as $A B C B 4$ and $A B C B 5 . A B C B 1$ and $A B C B 4$ in the human and mouse genomes are co-orthologous to $A B C B 1$ in the fish genomes, which was confirmed by a genomic syntenic analysis that showed that $A B C B 4$ occurred by duplication of $A B C B 1$ in mammals, estimated to be 170 million years ago, after the split of mammals from birds and reptiles [22]. An additional study also showed that $A B C B 1, A B C B 4$, and $A B C B 5$ were closely related and shared a common ancestor in chordate history [33]. $A B C B 5$ was thought to be specific to mammalian genomes [23], but was later discovered in non-mammalian genomes including teleost, birds, lizards, and Xenopus [22]. Here, we found that $A B C B 5$ appeared much earlier in the vertebrate lineage, in the lampreys.

$A B C B 6-A B C B 9$ and $A B C B 11$ are more conserved than other members of the $A B C B$ subfamily in chordate, as indicated by their presence in genomes from sea squirt to human. Furthermore, fish-specific genome duplication and species-specific duplication may have led to the emergence of $A B C B 6 b$ and $A B C B 11 b$ respectively in zebrafish (Fig. 2), as determined from an examination of $A B C B 6$ and $A B C B 11$ in teleost fish genome [22]. The ABCB2 (also known as antigen peptide transporter 1, TAP1) and ABCB3/TAP2 were not found in either sea squirts or lampreys, but are present in zebrafish and species that evolved later. The ABCB2 and ABCB3 proteins deliver peptides to the endoplasmic reticulum to form class I major histocompatibility complex (MHC) molecules [34], which controls a major part of the immune system in all vertebrates. MHCs display antigens on the cell surface for recognition by the appropriate T-cells. Thus, $A B C B 2$ and $A B C B 3$ are link to gnathostomes adaptive immune system. The timing of $\mathrm{ABCB} 2$ and $\mathrm{ABCB} 3$ appearance parallels the emergence of an adaptive immune system in gnathostomes. In lampreys, two additional $A B C B 1$-like and $A B C B 10$-like genes, named based on the highest similarity of their encoded proteins to the ABCB1 and $\mathrm{ABCB} 10$ proteins of mouse in BLASTP searches, were not well resolved in the phylogenetic analyses.

\section{ABCC subfamily}

Ten $A B C C$ genes were identified in lampreys, including $A B C C 1, A B C C 2, A B C C 3 a, \mathrm{ABCC} 3 \mathrm{~b}, A B C C 4, A B C C 5$, and $A B C C 7-A B C C 10$, all of which encode full $A B C$ transporters (Additional file 5: Figure S3). Only five of the 10
ABCC subfamily members were found in the previous study by Liu et al [22]. Moreover, the $A B C C 7$ fragment was mistakenly annotated as " $A B C C 4$ ", the short fragment of $A B C C 9$ was mistakenly annotated as " $A B C C 8-2$ ", and $A B C C 10$ was fragmented into two segments that were annotated as "ABCC10-1" and "ABCC10-2" (Additional file 3: Table S1). Of the $12 \mathrm{ABCC}$ members in human, $A B C C 6, A B C C 11$, and $A B C C 12$ were not found in the lampreys. In general, the phylogenetic analyses supported the names assigned to the $\mathrm{ABCC}$ genes in the lampreys (Fig. 3). Most lamprey ABCC proteins were positioned at the base of their respective clades with orthologous proteins from other species. Sea squirt $A B C C 1$ and $A B C C 2$ did not form separate clusters with orthologous genes from other species, but clustered with each other and then grouped with the subclade of $A B C C 1$ and $A B C C 3$ from other species. No $A B C C 3$ was found in sea squirts, but it was exclusively duplicated in lampreys. No $A B C C 6$ was identified in either sea squirts or lampreys. However, three copies of $A B C C 6$ were found in the zebrafish genome. Inferred from the phylogenetic tree, $A B C C 1$ and $A B C C 2$ in sea squirts may be the ancestral genes of $A B C C 1-A B C C 3$ and $A B C C 6 ; A B C C 6$ appeared after lampreys split with teleosts.

Three zebrafish ABCC8 proteins first grouped with human and mouse $\mathrm{ABCC} 8 \mathrm{~s}$ and then clustered with the ABCC9 subclade. Lamprey ABCC8 was placed at the root of the clade. No $A B C C 8$ or $A B C C 9$ genes were identified in sea squirts. These results suggested that $A B C C 8$ and $A B C C 9$ may have appeared after the speciation of sea squirts but before the speciation of lampreys. Sea squirt $A B C C 5$ is positioned at the base of the clade that includes $\mathrm{ABCC} 5$ and $\mathrm{ABCC} 12$ proteins from all the species, except for lamprey $\mathrm{ABCC} 12 . \mathrm{ABCC} 12$ may have been derived from the duplication of $A B C C 5$ and then underwent an independent gene loss in lampreys, or it was simply not found in the current incomplete lamprey draft genomes.

$A B C C 4$ was closely related to $A B C C 7$, which is not found in sea squirts but present in lampreys. Both $A B C C 11$ and $A B C C 13$ were not present in lampreys. $A B C C 11$ was found to have been duplicated tandemly from $A B C C 12$ in human [35]. $A B C C 13$ is present in zebrafish and is still functionally present in chicken, dog, and macaque, but is inactive in human, great apes, and mouse [36].

\section{$A B C D$ subfamily}

All members of the ABCD subfamily are half transporters located in the peroxisome with one TMD and one NBD [8]. All the genes in this subfamily are highly conserved in vertebrates and have undergone very few duplication or loss events. Three out of the four members of $\mathrm{ABCD}$ subfamily, $A B C D 2-A B C D 4$, were identified in both sea squirts and lampreys; $A B C D 3$ was not found by Liu et al (Additional file 3: Table S1). The 


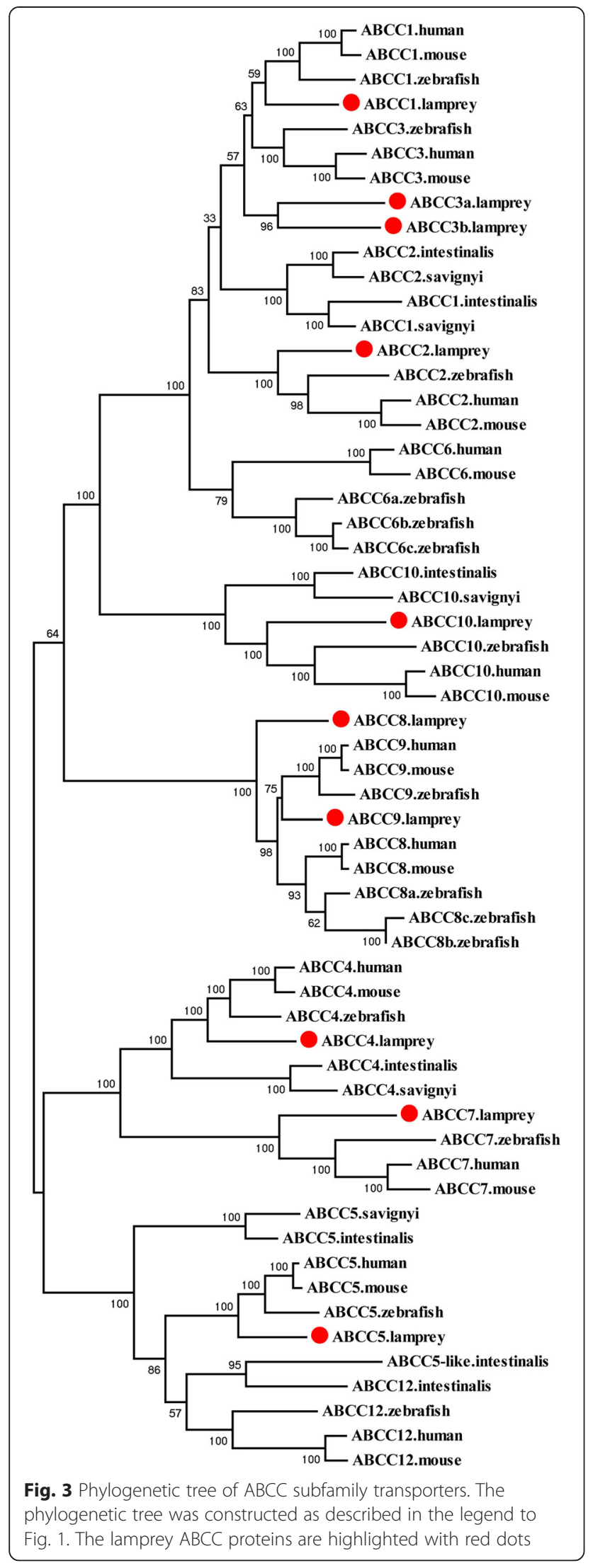

phylogenetic tree supports the assignment of $A B C D 2$, $\mathrm{ABCD} 3$, and $\mathrm{ABCD} 4$ in lampreys (Fig. 4). $A B C D 1$ was not identified in either lampreys or sea squirts. The $A B C D 1$ subclade clustered with the ABCD2 proteins of human, mouse, zebrafish, and lamprey, with the sea squirt $\mathrm{ABCD} 2$ positioned at the base of the clade. The phylogenetic tree indicates that $A B C D 1$ originated from the duplication of $A B C D 2$ before the divergence of lamprey with gnathostome and then underwent an independent gene loss in the lamprey lineage. Alternatively, $A B C D 1$ is present in the lamprey genome but was not found in the current incomplete lamprey genome assemblies. $A B C D 3$ had a single copy in lampreys, mouse, and human; but underwent duplication in fish-specific lineage including zebrafish and catfish [22].

\section{$A B C E$ and $A B C F$ subfamilies}

The $A B C E$ and $A B C F$ subfamilies consist of genes containing two NBDs with no TMDs (Table 1, Additional file 5: Figure S3). Members of the ABCE and $A B C F$ subfamilies were highly conserved in chordates; and each of the members identified in sea squirts was positioned at the base of the corresponding subclade. All the $A B C E$ and $A B C F$ members were identified by Liu et al, but $A B C F 3$ was split into two fragments and named " $A B C F 3$ 1" and "ABCF3-2" (Additional file 3: Table S1). The phylogenetic analysis supported the gene name assignment in

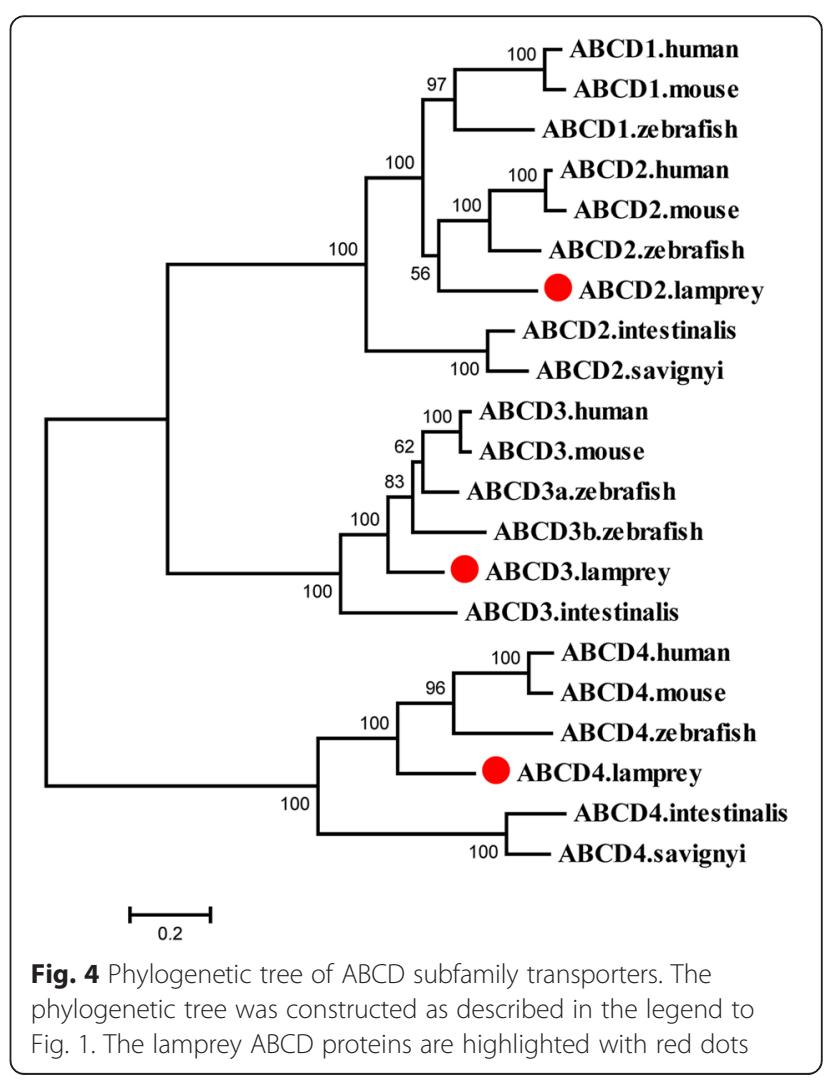


lamprey. Each member of the ABCE and ABCF subfamilies was present as a single-copy gene in most species. However, in some teleost fish, the members possessed more copies as a result of gene duplication; for example, there are two $A B C F 2$ genes in zebrafish (Fig. 5), and two $A B C E 1$ and $A B C F 2$ genes in catfish [22].

\section{ABCG subfamily}

All the ABCG transporters in metazoans are half transporters. Unlike other half transporters, the ABCGs have a reverse domain structure with a NBD at the N-terminus and a TMD at the $\mathrm{C}$-terminus. Only three members, $A B C G 2 a, A B C G 2 b$, and $A B C G 4$ were found in lampreys, and $A B C G 2 b$ was missed by Liu et al (Additional file 3: Table S1). In human, mouse, and zebrafish, the ABCG subfamily contains at least five members, $A B C G 1, A B C G 2$, $A B C G 4, A B C G 5$, and $A B C G 8$. In addition, $A B C G 3$ was present in mouse, and four copies of $A B C G 2$ and two copies of $A B C G 4$ were present in zebrafish (Fig. 6).

Notably, five $A B C G 1$-like genes were identified in sea squirts, which are rooted at the clade composed of the ABCG1 and ABCG4 subclades (Fig. 6). These data suggested that $A B C G 4$ was derived from the duplication of the $A B C G 1$-like1 gene before the speciation of lampreys and the remaining $A B C G 1$-like genes have undergone

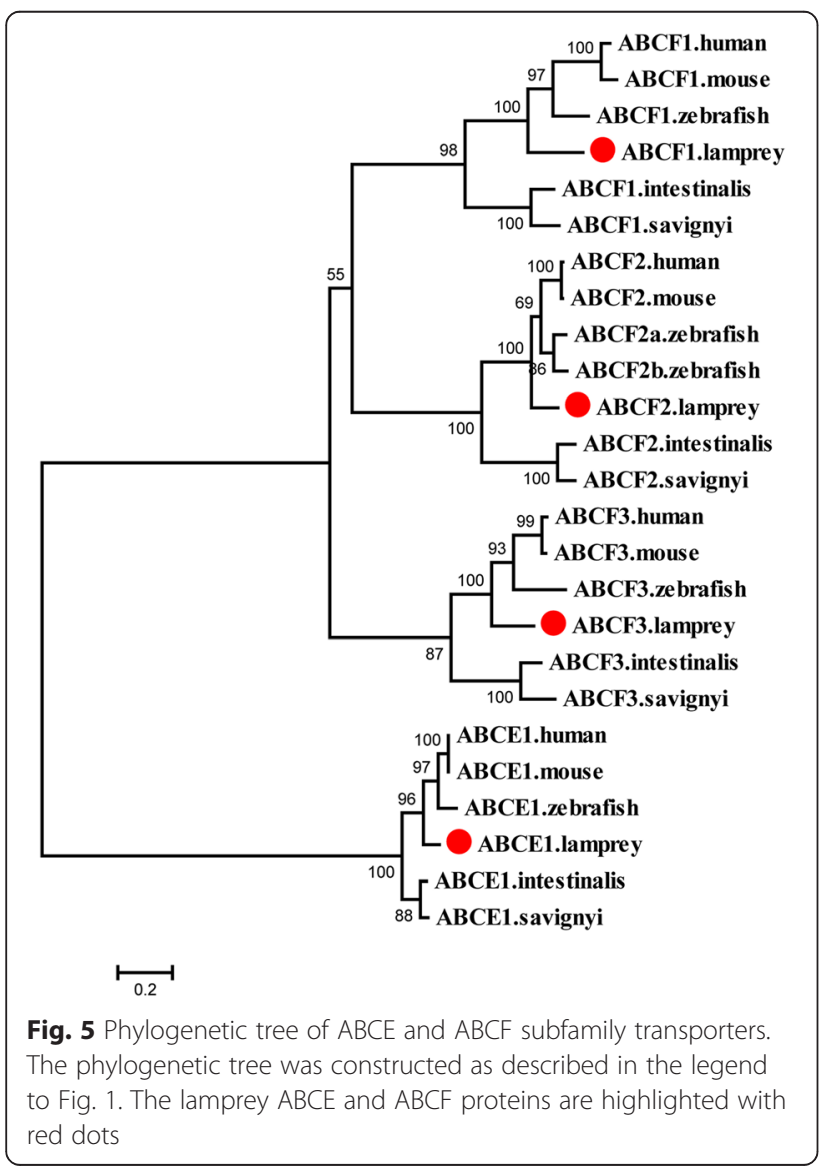

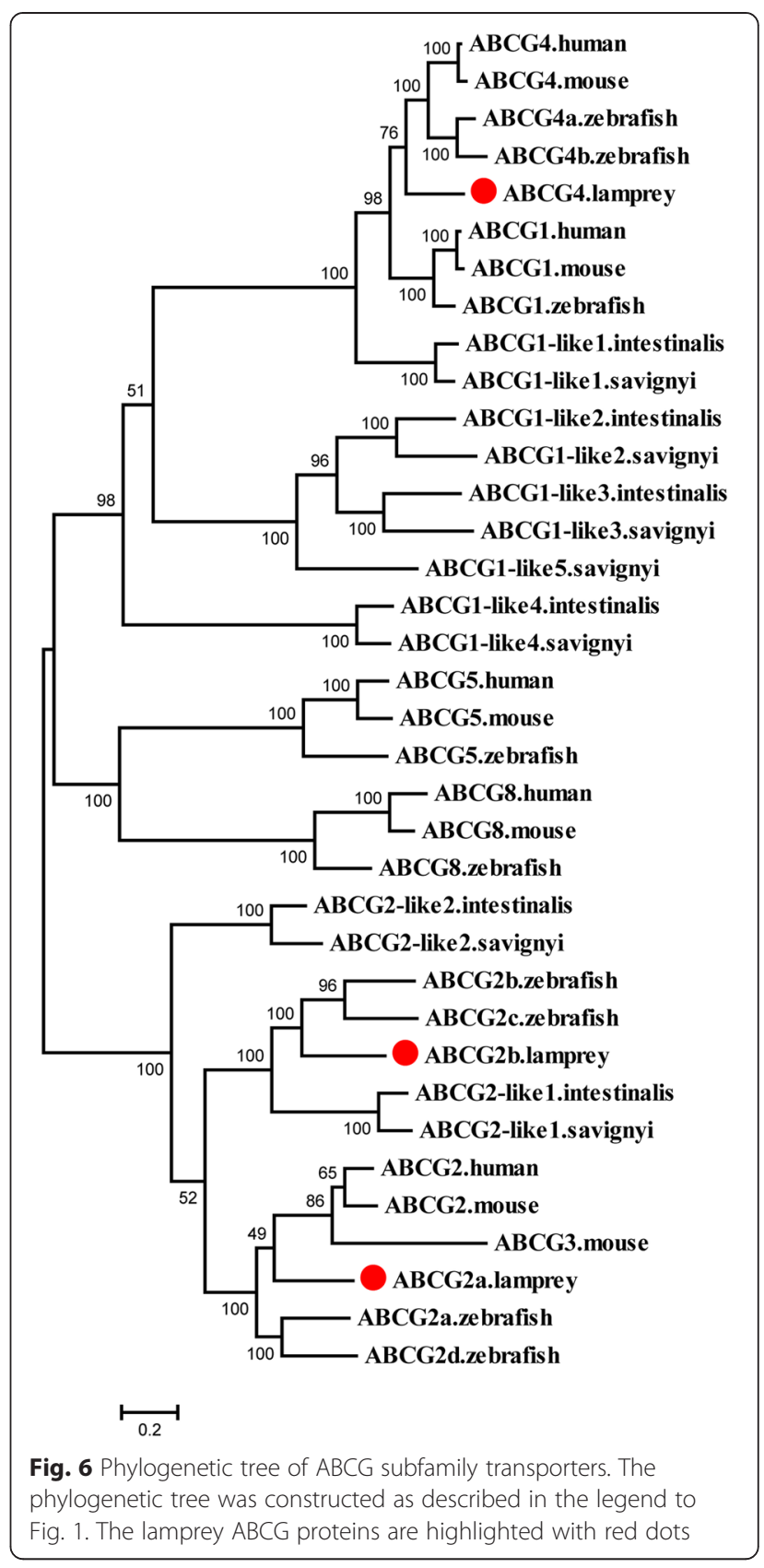

gene loss during vertebrate evolution. ABCG1 was not found in lamprey, suggesting that this gene may have been lost independently in the lamprey lineage or was not found because of the incomplete lamprey genome assembly.

$A B C G 5$ and ABCG8 arose from a common ancestral gene as evidenced from the head-to-head arrangement on a chromosome and the encoded proteins form a functional heterodimer [37]. The ABCG5 and ABCG8 proteins clustered together in the phylogenetic tree without orthologs in the lampreys and sea squirts. Two $A B C G 2$ members were identified in both sea squirts and lampreys and four $A B C G 2$ were present in zebrafish. 
The ABCG2 proteins in both lamprey and zebrafish were separated into two subclades; one ABCG2 in lampreys and two ABCG2s in zebrafish formed one subclade with the ABCG2-like1 gene in sea squirts. The ABCG2s in human, mouse, lamprey, and zebrafish clustered with mouse ABCG3 in the other subclade. Furthermore, the ABCG2like2 protein in sea squirts was placed at the base of the clade (Fig. 6). This result implies that the $A B C G 2$ genes derived from the $A B C G 2$-like1 in sea squirts underwent gene loss in the lineages after the divergence of teleost from other vertebrates. Conversely, the $A B C G 2$ genes derived from $A B C G 2$-like2 in sea squirts remained and duplicated to give rise to $A B C G 3$ in mouse.

\section{Expression profiling of $A B C$ genes in tissues across different developmental stages}

The expression levels of $\mathrm{ABC}$ genes were determined in sea lamprey tissues, including mature male rope, adult lips, supraneural, neutrophils, monocytes, and adult male gill (AMGill), and in tissues at different reproductive stages including prespermiating male gill (PSMGill), spermiating male gill (SMGill), preovulatory female eye (POFEye), preovulatory female tail skin (POFTS), ovulatory female head skin (OFHS), spermiating male head skin (SMHS), and spermiating male muscle (muscle). In addition, the expression levels of $\mathrm{ABC}$ genes in the intestine, kidney, and liver tissues across different developmental stages including larvae (M0), metamorphosis (M1-M7), juvenile, parasite, and adult stages were analyzed (Fig. 7, Additional file 6: Table S2).

The RNA-Seq data showed that all $37 \mathrm{ABC}$ genes were expressed $(\mathrm{RPM}>1)$ in at least one of the tissues (Additional file 6: Table S2). The ABCE and ABCF subfamily genes were ubiquitously and highly expressed in all the tested tissues. $A B C B 7$ and $A B C C 5$ were also ubiquitously and highly expressed, implying that these genes may play important roles in biological process in sea lamprey. Other genes were differentially expressed across various tissues. Within the same tissue, most of the $A B C$ genes were highly expressed at the larval stage and stages after metamorphosis, but relatively lowly expressed at metamorphosis stages.

Extensive functional studies of the $\mathrm{ABC}$ genes have been performed in human and mouse, but few studies have been carried out in lampreys [38, 39]. ABCA1 and ABCA4 are best studied members of the ABCA subfamily. In mammals, the ABCA1 protein is required for cholesterol efflux transport from peripheral cells into high-density lipoproteins particles $[40,41]$. The lamprey possessed two orthologs of $A B C A 1, A B C A 1 a$, and $A B C A 1 b . A B C A 1 a$ was ubiquitously and highly expressed in all tissues, especially in the tissues at the adult and mature stages,

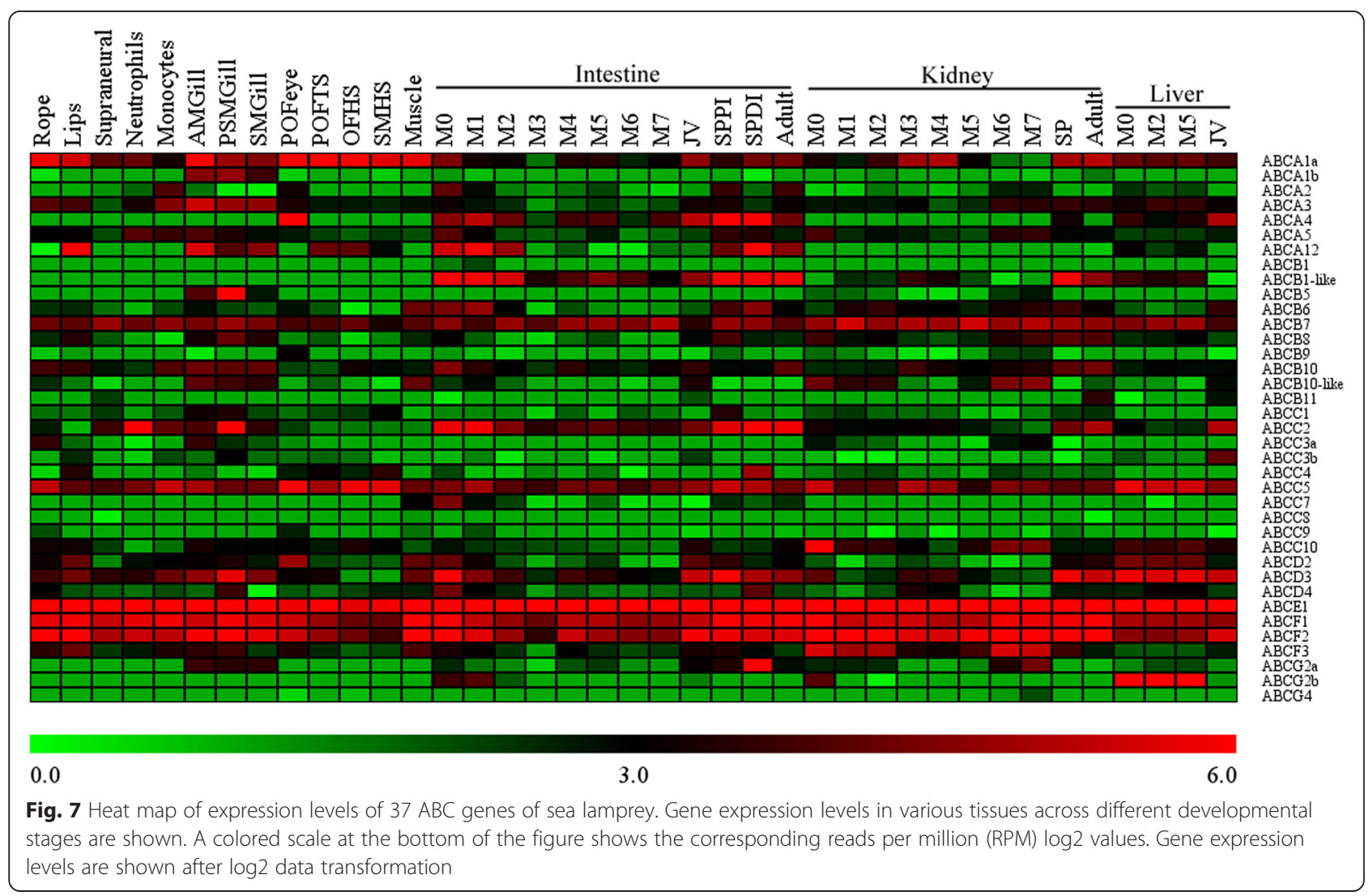


whereas $A B C A 1 b$ was highly expressed in the gill tissue (13-27 RPM). The ABCA4 protein, also known as photoreceptor rim protein $(\mathrm{RmP})$ or $\mathrm{ABCR}$, was expressed exclusively in the retina and is localized in the outer segment disk edges of rod photoreceptors [42]. Indeed, it is highly expressed in POFEye (162 RPM) and in intestine at M0 and M1 (24 and 38 RPM), and is especially highly expressed in the small parasite stages (261 and 773 RPM). This finding implies that the ABCA4 protein may perform multiple functions in early vertebrates and may have evolved to perform retina-specific function in mammals (human, mouse, and rodent) [43]. The ABCA12 protein appears to be essential for normal development of the skin. Several mutations in this gene have been reported to lead to severe skin disorders such as harlequin ichthyosis and lamellar ichthyosis type 2 in human [44, 45]. Although the exact function of ABCA12 is unknown, it probably plays an important role in transporting lipids into the cells that make up the epidermis [46]. ABCA12 is highly expressed in lip (134 RPM), adult gill (47 RPM), and intestines at M0 and M1 stages (42 and 76 RPM). It is also differentially expressed in different intestine regions at the small parasitic stage (small parasite distal intestine (SPDI), $293 \mathrm{RPM}$; and small parasite proximal intestine (SPPI), 18 RPM).

$\mathrm{ABCB} 1$ (P-gp or MDR1) functions in exporting foreign substances out of cells. The lamprey genomes contain two members of the $A B C B 1$ gene, $A B C B 1$ and $A B C B 1$ like. $A B C B 1$ showed no or low expression in all the tissues tested, whereas $A B C B 1$-like was highly expressed in intestine at the early stages of metamorphosis, M0-M2 (47-123 RPM), and at the small parasite and adult stages (63-130 RPM), as well as in kidney at the small parasite and adult stages (64 and 25 RPM). In human, $A B C B 5$ was expressed mainly in normal skin and malignant melanoma [47], while $A B C B 5$ was expressed in lamprey kidney and gill, with the highest expression level (80 RPM) in PSMGill.

The four half transporters, $\mathrm{ABCB} 6-\mathrm{ABCB} 8$ and $A B C B 10$, were localized in mitochondria where they were reported to function in iron metabolism and transport of $\mathrm{Fe} / \mathrm{S}$ protein precursors [48]. $A B C B 6$ was ubiquitously expressed (more than $1 \mathrm{RPM}$ ) in all tissues and highly expressed in muscle (19 RPM) and in intestines at the early metamorphic stages M0 and M1 (22 and 27 RPM), as well as in the small parasite stage (14 and 25 RPM). $A B C B 7$ was also ubiquitously expressed (more than $10 \mathrm{RPM}$ ) in all tissues. $A B C B 8$ was highly expressed (more than $10 \mathrm{RPM}$ ) in lips, gills, SPPI, and kidneys at metamorphic stages of M0, M6, and M7, and at the small parasite and adult stages. $A B C B 10$ was highly expressed in gills (18-19 RPM), in intestine at stages of M0 (23 RPM), and adult (17 RPM), and in kidney at the small parasite and adult stages (17 and 20 RPM). The expression pattern of $A B C B 10$-like was different from that of $A B C B 10$. In addition, $A B C B 10$-like was highly expressed in muscle and kidneys at metamorphic stages. ABCB11 (bile salt export pump, BSEP), is responsible for the transport of taurocholate and other cholate conjugates from hepatocytes to the bile. However, $A B C B 11$ was not expressed specifically in liver, but was also expressed in kidney [49] and, in general, we found that $A B C B 11$ was expressed at very low levels in most tissues, but was highly expressed in adult kidney and juvenile liver (12 and 7 RPM). This may be a compensatory mechanism in post-metamorphic lamprey that have lost the biliary tree [50].

$A B C C 1$ was expressed at low levels in all tissues; its highest expression levels were in SPPI and gills (about 10 RPM). $A B C C 2$ was expressed at relative high levels in all the tested tissues, and was especially high in neutrophils (67 RPM), PSMGill (150 RPM), and in intestines at stages of M0, M1, small parasite, and adult (52-67 RPM). In addition, $A B C C 2$ was highly expressed in kidney and liver after metamorphosis. Two copies of $A B C C 3, A B C C 3 a$, and $A B C C 3 b$ in lampreys were lowly expressed in all tissues. The highest expression levels (more than $10 \mathrm{RPM}$ ) of these genes were in rope, gill, and juvenile liver. $A B C C 4$ was highly expressed in lips (11 RPM) and SMHS (12 RPM), and differentially expressed in different intestine regions at the small parasite stages (SPPI $0.1 \mathrm{RPM}$, and SPDI $29 \mathrm{RPM}$ ). ABCC5 was ubiquitously and highly expressed in all tissues with the highest level in POFEye (106 RPM). ABCC7/CFTR encodes an ion channel that transports chloride and thiocyanate ions across epithelial cell membranes [51, 52]. Its expression levels were generally low in all tissues except for larval intestine (22 RPM). ABCC8 and ABCC9 function as modulators of ATP-sensitive potassium channels and for insulin release [53]. The expression levels of both $A B C C 8$ and $A B C C 9$ were generally low in all tissues. $A B C C 10$, which encodes a protein whose functions are unclear, was highly expressed in all tissues, especially in larval kidney (61 RPM).

$\mathrm{ABCD}$ homodimers are involved in the transport of very long chain acyl-CoA into the peroxisome [54]. ABCD2 was broadly expressed and its expression was especially high in lips (19 RPM), POFEye (28 RPM), muscle (18 RPM), and intestine at larva (18 RPM) and juvenile (17 RPM) stages. Its expression was relatively low in intestine and kidney at metamorphosis stages, but higher in liver at larval and metamorphic stages (18-21 RPM). ABCD3 is highly expressed in gill, intestine, and kidney at larval and post-metamorphic stages and in liver at all stages. The expression of $A B C D 4$ was generally low in all tissues, but in PSMGill and intestine its expression was more than 10 RPM at larva and parasitic stages.

$A B C E 1, \mathrm{ABCF} 1$, and $\mathrm{ABCF} 2$ were ubiquitously and highly expressed in all tissues. The gene expression 
patterns were consistent with the fundamental and essential functions of the encoded proteins in ribosome biogenesis and translation regulation $[9-11,19]$. The highest expression levels of $A B C E 1$ were found in adult intestine and kidney (368 and 347 RPM, respectively). ABCF3 was also ubiquitously expressed, but its expression was generally lower compared with $A B C E 1$, and $\mathrm{ABCF} 1$, and ABCF2.

The lamprey genomes contained two copies of $A B C G 2$. $A B C G 2 a$ was highly expressed in gills and kidney at M6 and M7 stages and the highest expression was found in intestine (SPDI 107 RPM). ABCG2b showed high expression in intestine and kidney at larval stage and the highest levels were found in liver at larval and metamorphic stages (109 and 132 RPM). ABCG4 was not expressed in all the tissues.

\section{Conclusions}

The first comprehensive analysis of $\mathrm{ABC}$ transporter genes were carried out in a primitive vertebrate lineage, the lampreys. A total of $37 \mathrm{ABC}$ transporter genes were identified. Thirteen more $A B C$ transporter genes were identified compared with a previous study. Through the concatenation of the gene sequences from two lamprey species, full length $A B C$ transporter sequences were obtained, which significantly improved the resolution of the name assignment and phylogenetic position for the genes compared with a previous analysis in which sequence fragments were used. In chordates, the $A B C$ transporter gene subfamilies have undergone obvious expansion or contraction. The ABCA subfamily showed the highest gene expansion rate during chordate evolution. All the genes in the $A B C D, A B C E$ and $A B C F$ subfamilies were highly conserved in the chordates. The evolution of $\mathrm{ABC}$ transporters in lampreys needs to be evaluated further because the results presented here are based on a draft genome.

\section{Methods}

\section{Identification of ABC transporter genes}

We used genomic resources, including the nucleotide and protein sequences of the sea lamprey and Japanese lamprey genomes, together with a sea lamprey transcriptome assembly of 89 RNA-Seq samples from various tissues across different developmental stages (unpublished data, Additional file 1: Figure S1), to identify lamprey $A B C$ transporter genes. All available $A B C$ transporter proteins of human, mouse and zebrafish were retrieved from GenBank or the Ensembl genome browser (release75) [55, 56] (Additional file 7: Table S3) and used as queries in standalone BLASTP or TBLASTN searches against the lamprey genomic resources. The coding regions in the retrieved RNA-Seq transcripts were predicted using the GETORF program in the EMBOSS online tool
(EMBOSS GUI v1.14; http://imed.med.ucm.es/cgi-bin/ emboss.pl?_action=input\&_app=getorf) [57], and the retrieved genomic sequences were subjected to $a b$ initio gene prediction using the Augustus program (http://bioi nf.uni-greifswald.de/augustus/) [58] and protein-based similarity gene prediction using FGENESH+ web server (http://www.softberry.com/) [59]. The final protein-coding sequences were validated by using them as queries in BLASTP searches against the NCBI non-redundant protein sequence database (nr). The conserved domains of the identified $A B C$ proteins were predicted using SMART (simple modular architecture research tool) [60] and confirmed using the NCBI CD-Search tool to predict conserved domains.

\section{Phylogenetic analysis}

All available $\mathrm{ABC}$ transporter proteins of human, mouse, zebrafish, and two sea squirts (C. intestinalis and $C$. savignyi) were retrieved from GenBank or the Ensembl genome browser (release75), and used for the phylogenetic analyses (Additional file 7: Table S3). The ABC transporter genes of $C$. intestinalis have been reported previously based on the genome assembly v1.0 at the Joint Genome Institute (JGI; http://genome.jgi-psf.org) [23]. Therefore, we downloaded the $\mathrm{ABC}$ transporter proteins of $C$. intestinalis from JGI and used them as queries in BLASTP searches against the protein sequences of $C$. intestinalis and $C$. savignyi from Ensembl. The three $A B C C$ subfamily members that were present in the JGI genome assembly v1.0 but were not in the Ensembl genome were included in the phylogenetic analysis.

Several of the ABC genes that were identified in both lamprey genomes were partial sequences. To compare the lamprey $A B C$ sequences with the $A B C$ sequences from the other vertebrate genomes, some of the $\mathrm{ABC}$ gene sequences from both lamprey genomes were concatenated to obtain longer sequences for the phylogenetic analyses. The concatenation of sequences from the two lamprey species was feasible because the nucleotide sequences in the protein-coding regions shared similarities of $97 \%$ or more between the two genomes. The concatenated $A B C$ sequences had a negligible effect on the topology of the phylogenetic tree. To improve the phylogenetic resolution, all the $\mathrm{ABC}$ transporter proteins were used to construct a tree and then the proteins within each subfamily were used to construct separate trees. The protein sequences for human, mouse, zebrafish, sea squirts, and the two lamprey were aligned using ClustalX 1.83 [61], then the multiple alignments were used to the phylogenetic tree using MEGA 6 [62] with 100 bootstrap replicates. The phylogenetic trees were constructed using the maximum likelihood method with the Jones-Taylor-Thornton (JTT) substitution model. The assignment of the lamprey $A B C$ proteins subfamily member was based on both the 
phylogenetic analysis and the highest similarity between the lamprey and mouse $\mathrm{ABC}$ proteins in the BLASTP searches.

\section{Quantification of $A B C$ gene expression}

The concatenated $\mathrm{ABC}$ gene sequences from both lamprey genomes were indexed as the reference sequences with Bowtie 1.0.0 [63]. RNA samples from an assortment of 89 tissues across different developmental stages were extracted using TRIzol method according to the manufacturer's instructions (Invitrogen, Foster City, CA, USA). The RNA was then poly-A selected, fragmented, and reverse transcribed to cDNA. The cDNA was sequenced using the Illumina GAII platform by the Research Technology Support Facility (RTSF) at Michigan State University using the Illumina mRNA-Seq 8-Sample Prep Kit. About 20 million reads, 75-100 nucleotides long, were obtained per sample giving a total of $1.5-2 \mathrm{~Gb}$ of mRNA-Seq sequencing reads. The reads were filtered, then trimmed using Trimmomatic [64], and aligned to the reference sequences using TopHat 1.4.1 with the default parameters [65]. The number of reads mapped to a specific gene was counted based on the BAM file. The gene expression level was calculated as the number of reads mapped to the specific gene relative to the total number of the filtered reads in the sample. The $\mathrm{ABC}$ gene expression level was normalized as RPM (the number of reads assigned to a gene per million reads). To better present the gene expression levels in the heat map, the expression values were transformed to $\log 2$ data. If the gene expression value was less than 1 RPM, it was assigned to 1 RPM. The gene expression values after the $\log 2$ data transformations are shown in the heat map, which was constructed using the $\mathrm{MeV}$ v4.0 package [66].

\section{Availability of supporting data}

The original data for phylogenetic analysis can be accessed on Dryad: doi:10.5061/dryad.k867f. The sea lamprey ABC gene sequences have been deposited in GenBank database (accession numbers: KM232912-KM232947) whereas the Japanese lamprey $\mathrm{ABC}$ gene sequences are included within the Additional file 2.

\section{Additional files}

Additional file 1: Figure S1. Tissues across developmental stages for mRNA-Seq.

Additional file 2: Sequences of $A B C$ transporter genes identified in Japanese lamprey.

Additional file 3: Table S1. Comparison of the lamprey ABC transporter genes between the Ensembl sequences and the sequences obtained in this study.

Additional file 4: Figure S2. Phylogenetic tree of all the $A B C$ transporter proteins used in this study.

Additional file 5: Figure S3. Functional domain organization in 37 lamprey $A B C$ transporters.
Additional file 6: Table S2. Tissues and expression values of ABC genes in sea lamprey.

Additional file 7: Table S3. All ABC transporter proteins retrieved and used in this study.

\section{Abbreviations}

ABC: ATP-binding cassette; TMD: Transmembrane domain; NBD: Nucleotidebinding domain; MDR: Multidrug resistance protein; MRP: Multidrug resistance associated protein; P-gp: P-glycoprotein; TAP: Transporter associated with antigen processing; CFTR: Cystic fibrosis transmembrane conductance regulator; ALD: Adrenoleukodystrophy; BSEP: Bile salt export pump; RPM: Reads per million mapped reads; AMGill: Adult male gill; PSMGill: Prespermiating male gill; SMGill: Spermiating male gill;

POFEye: Preovulatory female eye; POFTS: Preovulatory female tail skin; OFHS: Ovulatory female head skin; SMHS: Spermiating male head skin; SPPI: Small parasite proximal intestine; SPDI: Small parasite distal intestine.

\section{Competing interest}

The authors declare that they have no competing interests.

\section{Authors' contributions}

JR, CY and WL conceived the study; JR did data analysis and drafted the manuscript; CS and TB assembled the sea lamprey transcriptome; YCD, CY and WL wrote and revised the manuscript. All authors read and approved the final manuscript.

\section{Acknowledgements}

This work was supported by a grant of the Excellent Young Teachers Program of Shanghai (ZZHY13002) and Shanghai Universities First-class Disciplines Project of Fisheries.

\section{Author details}

'Key Laboratory of Exploration and Utilization of Aquatic Genetic Resources, College of Fisheries and Life Sciences, Shanghai Ocean University, Shanghai 201306, China. ${ }^{2}$ Department of Fisheries and Wildlife, Michigan State University, East Lansing, Ml 48824, USA. ${ }^{3}$ Department of Computer Science and Engineering, Michigan State University, East Lansing, MI 48824, USA. ${ }^{4}$ Department of Microbiology and Molecular Genetics, Michigan State University, East Lansing, Ml 48824, USA.

Received: 23 January 2015 Accepted: 1 June 2015 Published online: 06 June 2015

\section{References}

1. Dean M, Rzhetsky A, Allikmets R. The human ATP-binding cassette (ABC) transporter superfamily. Genome Res. 2001;11(7):1156-66.

2. Hollenstein K, Dawson RJ, Locher KP. Structure and mechanism of ABC transporter proteins. Curr Opin Struct Biol. 2007;17(4):412-8.

3. Locher KP. Review. Structure and mechanism of ATP-binding cassette transporters. Philos Trans R Soc Lond B Biol Sci. 2009;364(1514):239-45.

4. Davidson AL, Maloney PC. ABC transporters: how small machines do a big job. Trends Microbiol. 2007;15(10):448-55.

5. Rees $\mathrm{DC}$, Johnson $\mathrm{E}$, Lewinson $\mathrm{O}$. $\mathrm{ABC}$ transporters: the power to change. Nat Rev Mol Cell Biol. 2009;10(3):218-27.

6. Popovic M, Zaja R, Loncar J, Smital T. A novel ABC transporter: the first insight into zebrafish (Danio rerio) $\mathrm{ABCH}$. Mar Environ Res. 2010;69(Suppl):S11-3.

7. Dean M, Annilo T. Evolution of the ATP-binding cassette $(A B C)$ transporter superfamily in vertebrates. Annu Rev Genomics Hum Genet. 2005;6:123-42.

8. Vasiliou V, Vasiliou K, Nebert DW. Human ATP-binding cassette (ABC) transporter family. Hum Genomics. 2009;3(3):281-90.

9. Pisarev AV, Skabkin MA, Pisareva VP, Skabkina OV, Rakotondrafara AM, Hentze MW, et al. The role of ABCE1 in eukaryotic posttermination ribosomal recycling. Mol Cell. 2010;37(2):196-210.

10. Barthelme D, Dinkelaker S, Albers S-V, Londei P, Ermler U, Tampé R. Ribosome recycling depends on a mechanistic link between the FeS cluster domain and a conformational switch of the twin-ATPase ABCE1. Proc Natl Acad Sci. 2011;108(8):3228-33. 
11. Paytubi S, Wang X, Lam YW, Izquierdo L, Hunter MJ, Jan E, et al. ABC50 promotes translation initiation in mammalian cells. J Biol Chem. 2009;284(36):24061-73

12. Kartner N, Riordan JR, Ling V. Cell surface P-glycoprotein associated with multidrug resistance in mammalian cell lines. Science. 1983;221(4617):1285-8.

13. Moitra K, Dean M. Evolution of ABC transporters by gene duplication and their role in human disease. Biol Chem. 2011;392(1-2):29-37.

14. Dean M. The Human ATP-Binding Cassette (ABC) Transporter Superfamily. Bethesda (MD): National Center for Biotechnology Information (US); 2002; 2002.

15. Sheps JA, Ralph S, Zhao Z, Baillie DL, Ling V. The ABC transporter gene family of Caenorhabditis elegans has implications for the evolutionary dynamics of multidrug resistance in eukaryotes. Genome Biol. 2004;5(3):R15.

16. Roth CW, Holm I, Graille M, Dehoux P, Rzhetsky A, Wincker P, et al. Identification of the Anopheles gambiae ATP-binding cassette transporter superfamily genes. Mol Cells. 2003;15(2):150-8.

17. Liu S, Zhou S, Tian L, Guo E, Luan Y, Zhang J, et al. Genome-wide identification and characterization of ATP-binding cassette transporters in the silkworm, Bombyx mori. BMC Genomics. 2011;12:491.

18. Xie X, Cheng T, Wang G, Duan J, Niu W, Xia Q. Genome-wide analysis of the ATP-binding cassette $(A B C)$ transporter gene family in the silkworm, Bombyx mori. Mol Biol Rep. 2012;39(7):7281-91.

19. Broehan $\mathrm{G}$, Kroeger T, Lorenzen M, Merzendorfer $\mathrm{H}$. Functional analysis of the ATP-binding cassette (ABC) transporter gene family of Tribolium castaneum. BMC Genomics. 2013;14:6.

20. Sturm A, Cunningham $P$, Dean $M$. The $A B C$ transporter gene family of Daphnia pulex. BMC Genomics. 2009;10:170.

21. Dermauw W, Osborne EJ, Clark RM, Grbic M, Tirry L, Van Leeuwen T. A burst of $A B C$ genes in the genome of the polyphagous spider mite Tetranychus urticae. BMC Genomics. 2013;14:317.

22. Liu S, Li Q, Liu Z. Genome-wide identification, characterization and phylogenetic analysis of 50 catfish ATP-binding cassette (ABC) transporter genes. PLoS One. 2013;8(5):e63895.

23. Annilo T, Chen ZQ, Shulenin S, Costantino J, Thomas L, Lou H, et al. Evolution of the vertebrate $A B C$ gene family: analysis of gene birth and death. Genomics. 2006;88(1):1-11.

24. Smith JJ, Kuraku S, Holt C, Sauka-Spengler T, Jiang N, Campbell MS, et al. Sequencing of the sea lamprey (Petromyzon marinus) genome provides insights into vertebrate evolution. Nat Genet. 2013:45(4):415-21. 421e411-412.

25. Hardisty MW. Biology of the Cyclostomes. London: Chapman and Hall; 1979. p. 272-92.

26. Mehta TK, Ravi V, Yamasaki S, Lee AP, Lian MM, Tay B-H, et al. Evidence for at least six Hox clusters in the Japanese lamprey (Lethenteron japonicum), Proceedings of the National Academy of Sciences. 2013.

27. Smith JJ, Stuart AB, Sauka-Spengler T, Clifton SW, Amemiya CT. Development and analysis of a germline BAC resource for the sea lamprey, a vertebrate that undergoes substantial chromatin diminution. Chromosoma. 2010;119(4):381-9.

28. Smith JJ, Antonacci F, Eichler EE, Amemiya CT. Programmed loss of millions of base pairs from a vertebrate genome. Proc Natl Acad Sci U S A. 2009;106(27):11212-7.

29. Piehler AP, Wenzel JJ, Olstad OK, Haug KB, Kierulf P, Kaminski WE. The human ortholog of the rodent testis-specific $A B C$ transporter Abca17 is a ubiquitously expressed pseudogene (ABCA17P) and shares a common 5' end with ABCA3. BMC Mol Biol. 2006;7:28.

30. Chen ZQ, Annilo T, Shulenin S, Dean M. Three ATP-binding cassette transporter genes, Abca14, Abca15, and Abca16, form a cluster on mouse Chromosome 7F3. Mamm Genome. 2004;15(5):335-43.

31. Li G, Shi P, Wang Y. Evolutionary dynamics of the ABCA chromosome 17q24 cluster genes in vertebrates. Genomics. 2007;89(3):385-91.

32. Annilo T, Chen ZQ, Shulenin S, Dean M. Evolutionary analysis of a cluster of ATP-binding cassette (ABC) genes. Mamm Genome. 2003;14(1):7-20.

33. Moitra K, Scally M, McGee K, Lancaster G, Gold B, Dean M. Molecular evolutionary analysis of $A B C B 5$ : the ancestral gene is a full transporter with potentially deleterious single nucleotide polymorphisms. PLoS One. 2011;6(1):e16318

34. Michalova V, Murray BW, Sultmann H, Klein J. A contig map of the Mhc class I genomic region in the zebrafish reveals ancient synteny. J Immunol. 2000;164(10):5296-305.

35. Tammur J, Prades C, Arnould I, Rzhetsky A, Hutchinson A, Adachi M, et al. Two new genes from the human ATP-binding cassette transporter superfamily, $A B C C 11$ and $A B C C 12$, tandemly duplicated on chromosome 16q12. Gene. 2001;273(1):89-96.
36. Annilo T, Dean M. Degeneration of an ATP-binding cassette transporter gene, ABCC13, in different mammalian lineages. Genomics. 2004;84(1):34-46.

37. Remaley AT, Bark S, Walts AD, Freeman L, Shulenin S, Annilo T, et al. Comparative genome analysis of potential regulatory elements in the ABCG5-ABCG8 gene cluster. Biochem Biophys Res Commun. 2002;295(2):276-82.

38. Uinuk-ool TS, Mayer WE, Sato A, Takezaki N, Benyon L, Cooper MD, et al, Identification and characterization of a TAP-family gene in the lamprey. Immunogenetics. 2003;55(1):38-48.

39. Cai SY, Lionarons DA, Hagey L, Soroka CJ, Mennone A, Boyer JL. Adult sea lamprey tolerates biliary atresia by altering bile salt composition and renal excretion. Hepatology. 2013;57(6):2418-26.

40. Oram JF, Lawn RM. ABCA1. The gatekeeper for eliminating excess tissue cholesterol. J Lipid Res. 2001;42(8):1173-9.

41. Yvan-Charvet $L$, Wang $N$, Tall AR. Role of $H D L, A B C A 1$, and $A B C G 1$ transporters in cholesterol efflux and immune responses. Arterioscler Thromb Vasc Biol. 2010;30(2):139-43.

42. Sun H, Nathans J. ABCR: rod photoreceptor-specific ABC transporter responsible for Stargardt disease. Methods Enzymol. 2000;315:879-97.

43. Borst $P$, Elferink RO. Mammalian $A B C$ transporters in health and disease. Annu Rev Biochem. 2002;71:537-92.

44. Kelsell DP, Norgett EE, Unsworth H, Teh MT, Cullup T, Mein CA, et al. Mutations in $\mathrm{ABCA} 12$ underlie the severe congenital skin disease harlequin ichthyosis. Am J Hum Genet. 2005;76(5):794-803.

45. Lefevre C, Audebert S, Jobard F, Bouadjar B, Lakhdar H, BoughdeneStambouli $\mathrm{O}$, et al. Mutations in the transporter ABCA12 are associated with lamellar ichthyosis type 2. Hum Mol Genet. 2003;12(18):2369-78.

46. Akiyama M, Sugiyama-Nakagiri Y, Sakai K, McMillan JR, Goto M, Arita K, et al. Mutations in lipid transporter ABCA12 in harlequin ichthyosis and functional recovery by corrective gene transfer. J Clin Invest. 2005;115(7):1777-84.

47. Frank NY, Margaryan A, Huang Y, Schatton T, Waaga-Gasser AM, Gasser M, et al. ABCB5-mediated doxorubicin transport and chemoresistance in human malignant melanoma. Cancer Res. 2005;65(10):4320-33.

48. Zutz A, Gompf S, Schagger H, Tampe R. Mitochondrial ABC proteins in health and disease. Biochim Biophys Acta. 2009;1787(6):681-90.

49. Huls M, van den Heuvel JJ, Dijkman HB, Russel FG, Masereeuw R. ABC transporter expression profiling after ischemic reperfusion injury in mouse kidney. Kidney Int. 2006;69(12):2186-93.

50. Youson JH. Biliary atresia in lampreys. Adv Vet Sci Comp Med. 1993;37:197-255.

51. Riordan JR, Rommens JM, Kerem B, Alon N, Rozmahel R, Grzelczak Z, et al. Identification of the cystic fibrosis gene: cloning and characterization of complementary DNA. Science. 1989;245(4922):1066-73.

52. Childers M, Eckel G, Himmel A, Caldwell J. A new model of cystic fibrosis pathology: lack of transport of glutathione and its thiocyanate conjugates. Med Hypotheses. 2007;68(1):101-12.

53. Bryan J, Munoz A, Zhang X, Dufer M, Drews G, Krippeit-Drews P, et al. $A B C C 8$ and $A B C C 9: A B C$ transporters that regulate $K+$ channels. Pflugers Arch. 2007:453(5):703-18.

54. Morita M, Imanaka T. Peroxisomal ABC transporters: Structure, function and role in disease. Biochim Biophys Acta (BBA) - Mol Basis Dis. 2012;1822(9):1387-96.

55. Kersey PJ, Allen JE, Christensen M, Davis P, Falin LJ, Grabmueller C, et al. Ensembl Genomes 2013: scaling up access to genome-wide data. Nucleic Acids Res. 2014;42(Database issue):D546-52.

56. Pruitt KD, Brown GR, Hiatt SM, Thibaud-Nissen F, Astashyn A, Ermolaeva O, et al. RefSeq: an update on mammalian reference sequences. Nucleic Acids Res. 2014:42(Database issue):D756-63.

57. Rice P, Longden I, Bleasby A. EMBOSS: the European Molecular Biology Open Software Suite. Trends Genet. 2000;16(6):276-7.

58. Stanke M, Morgenstern B. AUGUSTUS: a web server for gene prediction in eukaryotes that allows user-defined constraints. Nucleic Acids Res. 2005;33(Web Server issue):W465-7.

59. Solovyev W. Statistical approaches in Eukaryotic gene prediction. In: Balding D, Cannings C, Bishop M, editors. Handbook of Statistical genetics. 3rd ed. 2007. p. 1616.

60. Letunic I, Doerks T, Bork P. SMART 7: recent updates to the protein domain annotation resource. Nucleic Acids Res. 2012;40(Database issue):D302-5.

61. Thompson JD, Gibson TJ, Plewniak F, Jeanmougin F, Higgins DG. The CLUSTAL_X windows interface: flexible strategies for multiple sequence alignment aided by quality analysis tools. Nucleic Acids Res. 1997;25(24):4876-82. 
62. Tamura K, Stecher G, Peterson D, Filipski A, Kumar S. MEGA6: Molecular Evolutionary Genetics Analysis version 6.0. Mol Biol Evol. 2013;30(12):2725-9.

63. Langmead B, Trapnell C, Pop M, Salzberg SL. Ultrafast and memory-efficient alignment of short DNA sequences to the human genome. Genome Biol. 2009;10(3):R25.

64. Bolger AM, Lohse M, Usadel B. Trimmomatic: a flexible trimmer for Illumina sequence data. Bioinformatics. 2014;30(15):2114-2120.

65. Trapnell C, Pachter L, Salzberg SL. TopHat: discovering splice junctions with RNA-Seq. Bioinformatics. 2009;25(9):1105-11.

66. Saeed Al, Sharov V, White J, Li J, Liang W, Bhagabati N, et al. TM4: a free, open-source system for microarray data management and analysis. Biotechniques. 2003;34(2):374-8.

\section{Submit your next manuscript to BioMed Central and take full advantage of:}

- Convenient online submission

- Thorough peer review

- No space constraints or color figure charges

- Immediate publication on acceptance

- Inclusion in PubMed, CAS, Scopus and Google Scholar

- Research which is freely available for redistribution 